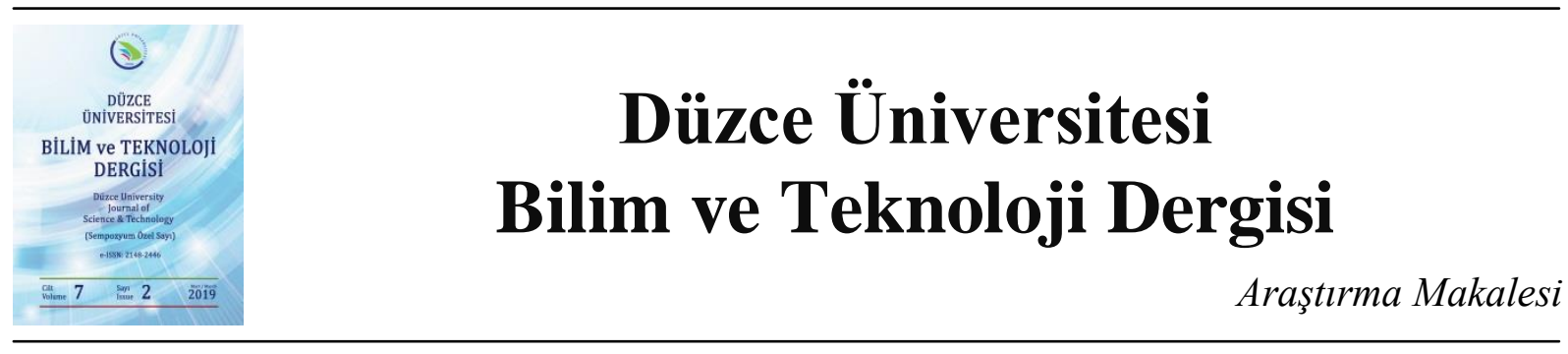

\section{Yeni Bir Çim Biçme Makinesinin Kavramsal Tasarımı}

\author{
Hüseyin R. BÖRKLÜ ${ }^{\text {a }}$, Fulya ERDEMIR ${ }^{\text {b, * }}$ \\ ${ }^{a}$ Endüstriyel Tasartm Mühendisliği Bölümü, Teknoloji Fakültesi, Gazi Üniversitesi, Ankara, TÜRKIYYE \\ b Endüstriyel Tasarım Mühendisliği Ana Bilim Dall, Fen Bilimleri Enstitüsü, Gazi Üniversitesi, Ankara, \\ TÜRKIYE \\ * Sorumlu yazarın e-posta adresi: erdemirfulya@gmail.com.tr
}

\begin{abstract}
$\underline{\text { ÖZET }}$
Yeşil alanlar insana huzur ve ferahlık verir. Ayrıca bu tür alanlar, insan ve diğer canlılara, dinlenme, eğlenme ve oyun imkânı da sağlar. Yine bu alanlar, yağışlı zamanlarda çamur oluşumunu ve kuru havalarda ise toz oluşumunu önleyerek çevre temizliğine katkı sağlar. Ancak, büyük park ve bahçelerdeki çimli alanların bakımı zor, zaman alıcı ve zahmetlidir. Bu çalışma kapsamında şehirlerdeki sitelerde kullanılacak inovatif bir çim biçme makinesinin kavramsal tasarımı tanıtılmaktadır. Bu tasarım işlemi Pahl ve Beitz'in sistematik tasarım yaklaşımına dayanmaktadır. Bu kavramsal tasarım çalışması; fonksiyon şeması, alt ve genel tasarımlar, ön değerlendirme, tasarım çözümleri, ek seçim işlemleri ve değerlendirme- son karar aşamalarından oluşmuştur. Her bir aşama ayrı ayrı tasarım bakış açısından irdelenmiş ve üründe istene fonksiyonların bulunduğu ara tasarım seçenekleri belirlenmiş ve tasarım fonksiyonu olarak performansı en yüksek olan tasarım seçeneği seçilmiştir.
\end{abstract}

Anahtar Kelimeler: Çim Biçme Makinesi, Sistematik Tasarım Yaklaşımı, Kavramsal Tasarım

\section{Conceptual Design of An İnnovative Lawn Mower Machine}

\begin{abstract}
Green spaces give people peace and relaxation. In addition, such areas provide human and other living, recreation, entertainment and play facilities. These areas also contribute to the cleanliness of the environment by preventing the formation of dust in mud and dry piles in rainy times. However, maintenance of large parks and grassy areas in gardens is difficult, time consuming and laborious. This paper introduces the conceptual design of an innovative lawnmower to be used in cities. This design process is based on the systematic design approach of Pahl and Beitz. This conceptual design study; Function diagram, sub and general designs, pre-evaluation, design solutions, additional selection procedures and evaluation-final decision stages. Each stage was examined separately from the design point of view and the intermediate design options with the desired functions in the product were determined and the design which has the highest performance as the design function was selected.
\end{abstract}

Keywords: Lawn Mower, Systematic Design Approach, Conceptual Design 


\section{GiRis}

Y eşil alanlar insana huzur ve sükûnet verir. Çimler, toprağı kaplayan doğal bir örtü oldukları gibi insan ve tüm canlıların oyun, eğlenme ve dinlenme gibi faaliyetlerinde kolaylık sağlar. Ayrıca, park ve bahçe yapım ve düzenlemede çok önem taşır. Bu tür alanlarda bulunan ağaç ve çiçekler için güzel bir fon oluşturup diğer bitkilerin güzelliğini ortaya çıkarır [1]. Çim yüzeyinin kaliteli elde edilmesinde, yoğun ve güzel görünmesinde çim biçme işleminin düzenli yapılması önem taşımaktadır. Çim boyutunun uygun boyutlarda olması çim biçmenin en kritik noktalarından birini oluşturmaktadır [2]. Geçmişten günümüze çim bakımı için çeşitli makineler geliştirilmiştir. Bir çim kesme makinesi birkaç dönen bıçak kullanıp belirli bir yükseklikte çimi kesebilmektedir. Çim kesme yüksekliği makineye göre sabit olmakta veya ayarlanabilmektedir. İlk çim biçme makinesi 1830 yılında İngiltere'de E.Budding tarafindan geliştirilmiştir. 1832'de üretilmeye başlanan bu makine büyük park/bahçeler ve futbol/tenis/golf/kriket vb. sahaların bakımında kullanılmıştır [3]. Oldukça büyük, hantal ve kullanışsız olan bu ilk makineler yeni bir iş kolu oluşmasını sağlamıştır. 1850'de görülen yeni modeller 1860'dan itibaren çok artmış ve üretim hızlanmıştır. Motorlu ilk çim biçme makineleri ise 1893 'de Benz şirketi (Stuttgart'ta) ve Coldwell Lawn Mower şirketi tarafindan üretilmiş ve test edilmiştir. Yine Amerika'da ilk çim traktörü (triplex) 1922'de üretilmiştir [4]. Çim biçme makinesinin ana amacı korunmakla birlikte tasarımda kullanılan enerji, kullanılan kesme bıçak şekilleri, yükseklik ayarlanabilme özelliği, malçlama (doğal gübreleme) yapabilme ve hazneye depolayabilme gibi özelliklerle yenilenmiş ve geliştirilmiştir. George L Rowe ve Herbert P Spindler, bir çim biçme makinesinin manüel bir şekilde istenilen yükseklik ayarı yapılarak çim biçme işlemini sağlayan bir mekanizma tasarlamıştır [5]. Robert D. Davis ve James S. Schucker, ticari tesis ve golf sahaları gibi alanlarda kullanılmak üzere bir çim biçme makinesi tasarlamıştır. Tasarlanan makine önceki tekniklerde $90^{\circ}$ olan bükmeli kayış tahriki yerine $45^{\circ}$ yapılmış bu şekilde ömrü uzatılmıştır. Direksiyon, fren, ileri ve geri hız kontrolüne sahip olan makine ikiz sönümlemeyle engebeli arazide uyumlu çalışabilme gibi özelliklerle donatılmıştır [6]. Luis Marcial Medina, ileri-geri, dönme, hız işlemini gerçekleştiren bir mikro işlemciye sahip çimleri kesmek ve elektrik üretmek için gaz motoru bulunan hibrit uzaktan kumandalı bir çim biçme makinesi tasarlamıştır [7]. Jonathan Björn ve Patrik Jägenstedt ise Husqvarna için robotik bir çim biçme makinesi tasarlamıştır. Tasarlanan robotik çim biçme makinesinin devre dışı bırakılmış bir durumda olduğu bir kapalı konum, duruş halinde olduğu bir duruş pozisyonunu ve aktif durumda olduğu bir açık pozisyon olmak üzere 3 pozisyondan oluşmaktadır [8].

Bir kavramsal tasarım ürünün ana özelliklerinin belirlenmesi aşamasıdır. Sistematik bir yaklaşımla hangi alanda olursa olsun bir ürüne dönüşüm süresinde kavramsal tasarım uygulanmaktadır. Pahl ve Beitz, bir tasarımı içerik bakımından orijinal tasarım, adapte edilen tasarım, geçiş tasarımı ve değişken tasarım olmak üzere 4 ayrı şekilde incelemiştir. Tasarımcılara yardımcı olmak için bir tasarım metodunda olması gereken özellikleri tanımlamıştır. Bu bağlamda sistematik bir tasarım yaklaşımı sunmuştur [9]. M. Bozdemir Ve İ.Toktaş, çalışmalarında bir oto servis lifti örneği kullanarak mekanik sistemlerin kavramsal tasarımı için sistematik bir yaklaşım sunmuştur [10]. M. Mayda ve H.R. Börklü ise çalışmalarında, 'Sistematik tasarım' yaklaşımını temel alan ve bilgisayar destekli kavramsal tasarım için bir alt yapı sağlayan bir kavramsal tasarım işlem modeli geliştirmiştir [11].

Çim biçme makineleri genel olarak yatay ve dikey şeklinde iki gruba ayrılarak incelenmiştir. Silindir bıçaklar çimi hızlı keserken toprağa da baskı yaparak çim -toprak temasını keser ve çimin yatay gelişimini kolaylaştırır [3, 12]. Yatay çim biçme makineleri dikey milden aldığı hareketi çimlere 
dairesel şekilde uygulayarak kesme işlemi yapar. $\mathrm{Bu}$ tür makineler genelde dört teker üzerine kurulmuş üfürme sistemi, kuvvetli şase, kol, motor, bıçak adaptörü ve dairesel biçimi sağlayan bıçak içerir $[3,12]$. Modern çim kesme makineleri; manuel, benzin motorlu, akü veya şebekeden beslenen elektrik motorlu ve güneş enerjisi kullanan (yine elektrik motorlu) vb. şekilde çalışmaktadır. Küçük (itmeli), orta ve büyük (araç/traktör) gibi çeşitleri vardır [3,14]. Küçük tipler ev bahçeleri ve büyük tipler ise büyük yerler/parklar için uygundur. Bu çalışma kapsamında kavramsal tasarım metodu ile tasarlanan çevre dostu ve güneş enerjisi ile şarj edilebilen aküye sahip bir çim biçme makinesi ele alınmaktadır.

\section{II. Çì BiçME MAKINESİ TASARIMI}

$\mathrm{Bu}$ kısımda Sistematik Tasarım Yaklaşımı kullanılarak yapılan yeni ve inovatif bir çim biçme makinesinin kavramsal tasarımı ele alınmaktadır. Yeşillik ve doğanın her insanın içini ferahlattığı bir gerçektir. Modernleşme ile birlikte günümüz kentlerinde arazilerin büyük kısmında siteler ve hatta küçük şehirler oluşmaya başlamıştır. Yoğun tempo ve stres altında çalışan insanlar binalar arasında nefes alacak yeşil alan ve manzaralar olmasını istemektedir. Bu ve buna benzer nedenlerden ötürü çim alanlar artmaktadır. Bu alanların bakımı için de; çim biçme makinesi, ilaçlar,gübre ve gübreleme sistemi,sulama sistemi vb. gibi ihtiyaçlar doğmaktadır. Ayrıca güzel ve yoğun bir çim yüzeyi için buraların belirli zamanlarda biçilmesi gerekmektedir. Bu çalışma, çim biçme işleminde kullanılacak yeni/inovatif bir çim biçme makinesi kavramsal tasarımını içermektedir. İşlem altı aşamadan oluşmaktadır [15,16]. Bu aşamalar; (A) İhtiyaç listesi, (B) Fonksiyon şeması, (C) Alt ve genel tasarımlar, (D) Ön değerlendirme, (E) Önemli tasarımlar ve (F) Ek seçim işlemleri. Yapılan tasarım bu başlıklar altında aşağıda tanıtılmaktadır.

\section{A. IHTTIYAÇ LISTESI}

Çim biçme makinesi kavramsal tasarımı için hazırlanmış örnek bir ihtiyaç listesi (tasarım şartnamesi) Tablo 1'de görülmektedir [14]. Bu ihtiyaç listesinde tasarlanacak çim biçme makinesine ait; geometrik büyüklük ve taşıma kolaylığı, kolay muhafaza edilmesi, ergonomik tutamakları olması, güç kullanımı ve bakımı gibi özellikler yer almaktadır. Bu aşamada genelde kavramsal tasarım süreci için gerekli ihtiyaçlar vardır ve gerekirse bunlar tasarımın gelişmesine bağlı olarak esnetilebilir. İhtiyaç listesinde yer alan özelliklerden ihtiyaçlar, tasarım çözümü tarafından mutlaka karşılanması gerekirken arzular (A) ise teknolojik ve ekonomik şartlar elverdiği ölçüde dikkate alınmaktadır.

Tablo 1. Tasarlanması planlanan çim biçme makinesinin ihtiyaç listesi, Arzular (A) ile gösterilmiştir.

\section{SIRA ISTENILEN ÖZELLIKLER/IHTIYAÇLAR}

\begin{tabular}{cl}
\hline 1 & Makine $400 \leq$ arazi $\leq 600 \mathrm{~m}^{2}$ için uygun olmalı \\
2 & Makine mümkün olduğunca hafif ve taşınabilir olmalı \\
3 & Kullanımı kolay/basit olmalı \\
4 & Az enerji tüketmeli \\
5 & (A) Malçlama (Doğal gübreleme) özelliğine sahip olmalı \\
6 & Kesme genişliği $\leq 40 \mathrm{~cm}$ olmalı \\
7 & Ayarlanabilir makine yüksekliğine sahip olmalı \\
8 & $35 \leq$ Çim toplama kapasitesi $\leq 70$ litre arası olmalı \\
9 & (A) Aynı zamanda sulama yapabilmeli \\
10 & Ergonomik tutamaklara sahip olmalı
\end{tabular}


11 Zor şartlar altında bile güvenli kesim sağlamalı

12 Kolay montaj edilebilmeli

13 Kullanılan malzemeler çevre dostu olmalı

14 (A) Çim biçme tarağına sahip olmalı

15 Gürültü emisyon ölçümü $\leq 94 \mathrm{~dB}$ (A)

16 Kesme bıçakları paslanmaz çelikten yapılmalı

17 Kolay muhafaza edilebilir olmalı

18 Makinenin temizliği kolay yapılabilmeli

\section{B. FONKSIYON SEMASI}

$\mathrm{Bu}$ kısımda sisteme $\mathrm{E}$ (enerji) (kimyasal ve mekanik), S(sinyal) ve $\mathrm{M}$ (malzeme) girmekte ve makinenin işlevini yapması sonucu dışarı çıkmaktadır. İşlem sonucunda çim biçme makinesi çimleri toplama haznesinde sıkıştırarak biriktirecektir. Tablo 1'de verilen ihtiyaç listesine uygun bir çim biçme makinesine ait hazırlanan fonksiyon şeması Şekil 2'de gösterilmektedir. Bu şemalar birden fazla hazırlanmış olmakla birlikte burada bunlardan sadece biri (optimumu) gösterilmiştir. Şemada yer alan ana fonksiyon blokları (alt fonksiyonlar); biçme yüksekliğini ayarla, tutamağı kavra, makineyi çalıştır, çimleri biç, biçilen çimleri hazneye vakumla, kesilen çimleri sıkıştır, çimleri sepete depola şeklindedir. Yardımcı fonksiyonlar ise; şarj gösterimi ve başlık değiştir olarak belirlenmiştir. Şekil 2'deki fonksiyon şeması ve buradaki alt fonksiyonlar bir sonraki aşamada alt çözümlerin bulunmasında kullanılmaktadır [15].

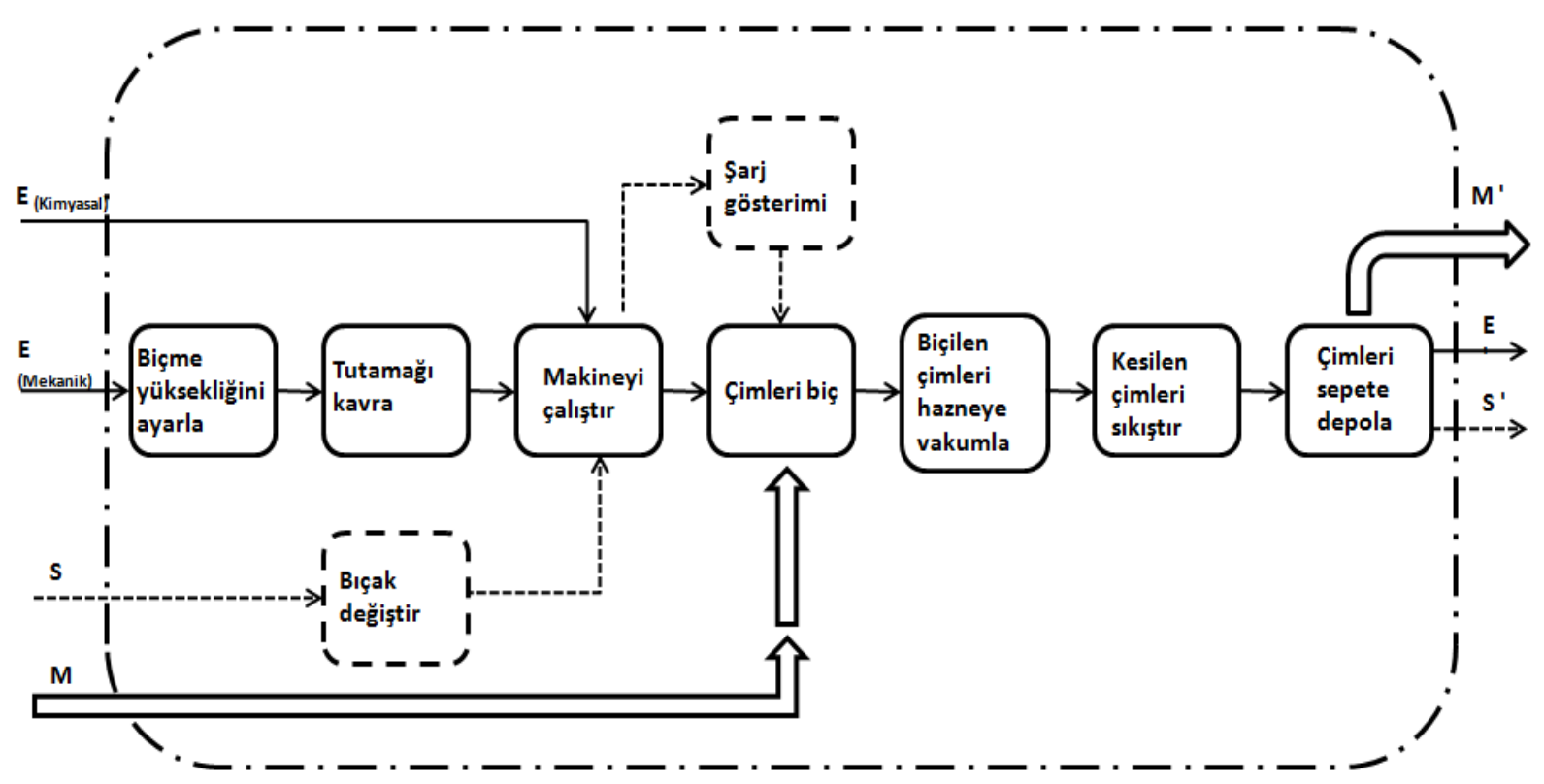

Şekil 2. Çim biçme makinesine ait fonksiyon şeması

\section{ALT ve GENEL TASARIMLAR}

Şekil 2'de yer alan fonksiyon şeması, kavramsal tasarımı yapılan çim biçme makinesini işlevsel alt parçalara bölmektedir. Ayrıca bu parçalar arası ilişkiler ve veri akışları da (E, S ve M cinsinden) bu şemada görülmektedir. Fonksiyon şemasındaki önemli/ana fonksiyonlar Şekil 3'te görülen matriste 
satırlara ve bunların olası çözümleri de hizalarına girilmek sureti ile alt tasarımlar elde edilmektedir. Bunlar sırayla; enerji türü, gövde tasarımı, bıçak tasarımı, tutamak tasarımı, tekerlek tasarımı ve yükseklik ayarı şeklindedir. Daha sonra bu fonksiyonlara uygun olası alt çözümler aynı satırdaki hücrelerde gösterilmektedir. Son olarak bu çözüm ilkeleri arasında tercihler yapılarak tüm sisteme ait 6 farklı çözüm seçeneği (tasarım varyantı) oluşturulmaktadır.

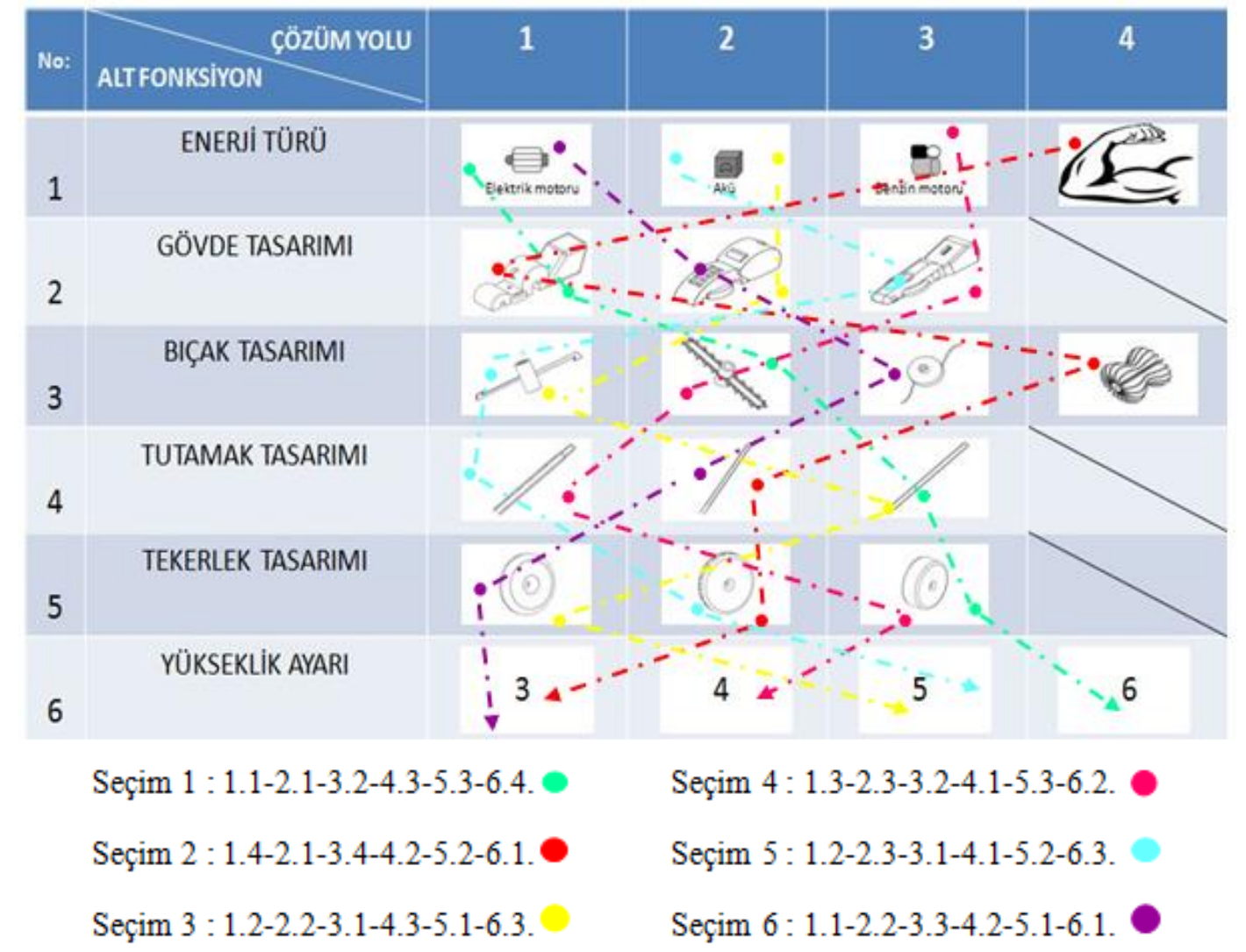

Şekil 3. Çim biçme makinesine ait morfolojik kart ve ilişkili kavram varyantları [11]

\section{D. ÖN DE $\breve{G E R L E N D I R M E ~}$}

Çim biçme makinesi tasarımı için; ihtiyaç listesi (problem tanımı), fonksiyon şeması (tasarım formüle etme ve küçük alt işlevsel parçaları), morfolojik matris (alt parça çözümleri ve birleşim varyantları) hazırlanmaktadır. Böylece tüm sisteme ait 6 farklı alternatif tasarım çözümü yapılmaktadır. $\mathrm{Bu}$ alternatif çözüm önerileri çim biçme makinesine en uygun tasarım seçenekleridir. Buna ek olarak optimum tasarımı bulmak için bu çözümleri bazı kriterlere göre değerlendirmek gerekmektedir. Bu bağlamda Şekil 4’te de göründügü gibi seçim kartı kullanılmakta, optimum çözüme en uygun olan üç tasarım seçeneği belirlenmekte ve diğer üçü ise elenmektedir. 


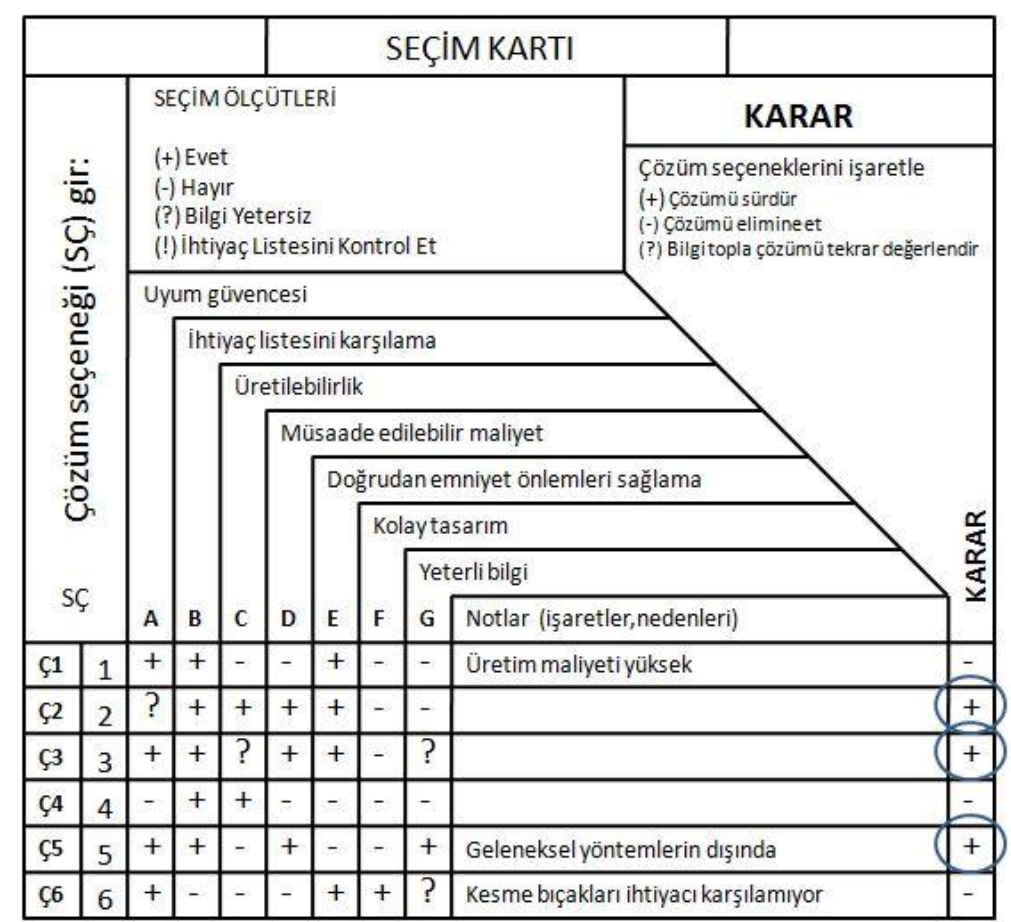

Şekil 4. Çim biçme makinesi kavramsal tasarım ön değerlendirmesi (seçim kartı)

\section{E. TASARIM ÇÖZÜMLERI}

Seçim kartı kullanılarak elde edilen önemli çözümler Şekil 5-7'de gösterilmiştir. Bunlardan ilki Şekil 5 de gösterilen 2 nolu seçim; yüksekliği ayarlanabilir ergonomik tutamaklara, kullanışlı bir plastik gövdeye, 40 litre hacimli kolay boşaltılabilir bir toplama haznesine, yeri sağlam ve dengeli tutan tekerleklere, 3 kademeli silindirik bıçaklara sahip ve kas gücü ile çalışan bir makinedir. Şekil 6'da gösterilen 3 nolu seçim; ergonomik tutamaklara sahip, sıkıştırıp depolama yapabilen 50 litrelik çim haznesi bulunan, 5 kademe ayarlanabilir çelik bıçakları olan, hareket kolaylığı sağlayan küçük tekerlek ve güneş panelleri ile aküyü şarj eden özeliklere sahip bir makinedir.

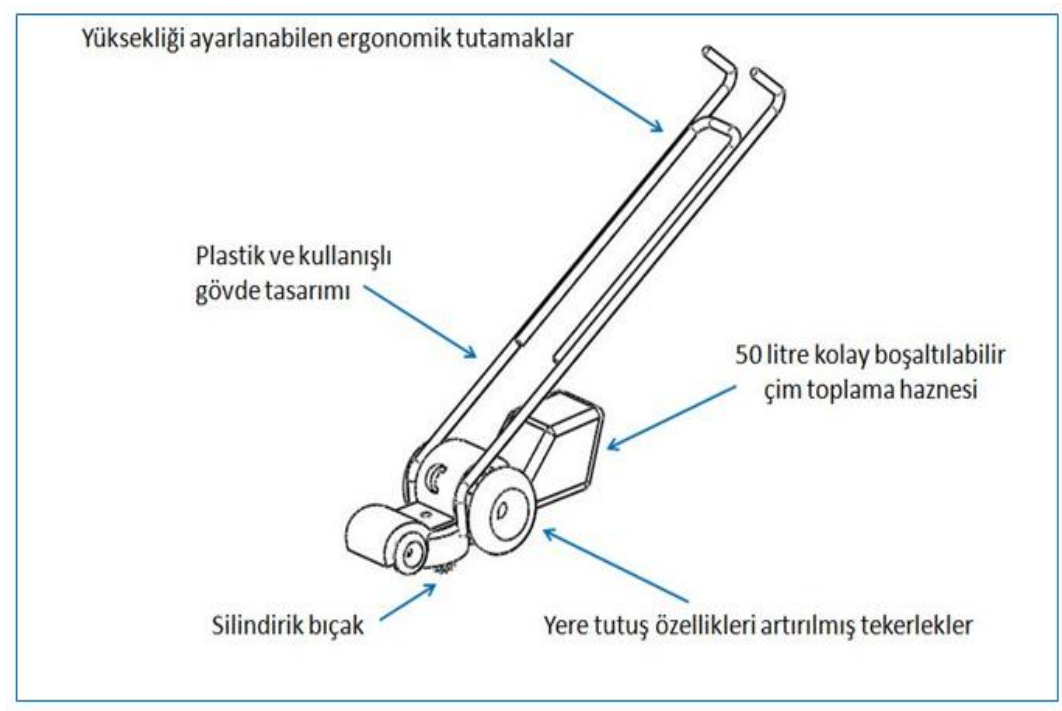

Şekil 5. Çim biçme makinesi kavramsal tasarımlar (Seçim 2) 
Şekil 7'de yer alan 5 nolu seçim ise, yüksekliği ayarlanabilir ergonomik tutamaklara, 60 litre kolay boşaltılabilir çim haznesi, kolay taşınabilir sapa, yeri sağlam tutan tekerleklere, 5 kademeli çelik bıçaklara ve elektrikle şarj olan aküye sahip bir makinedir [15,17].

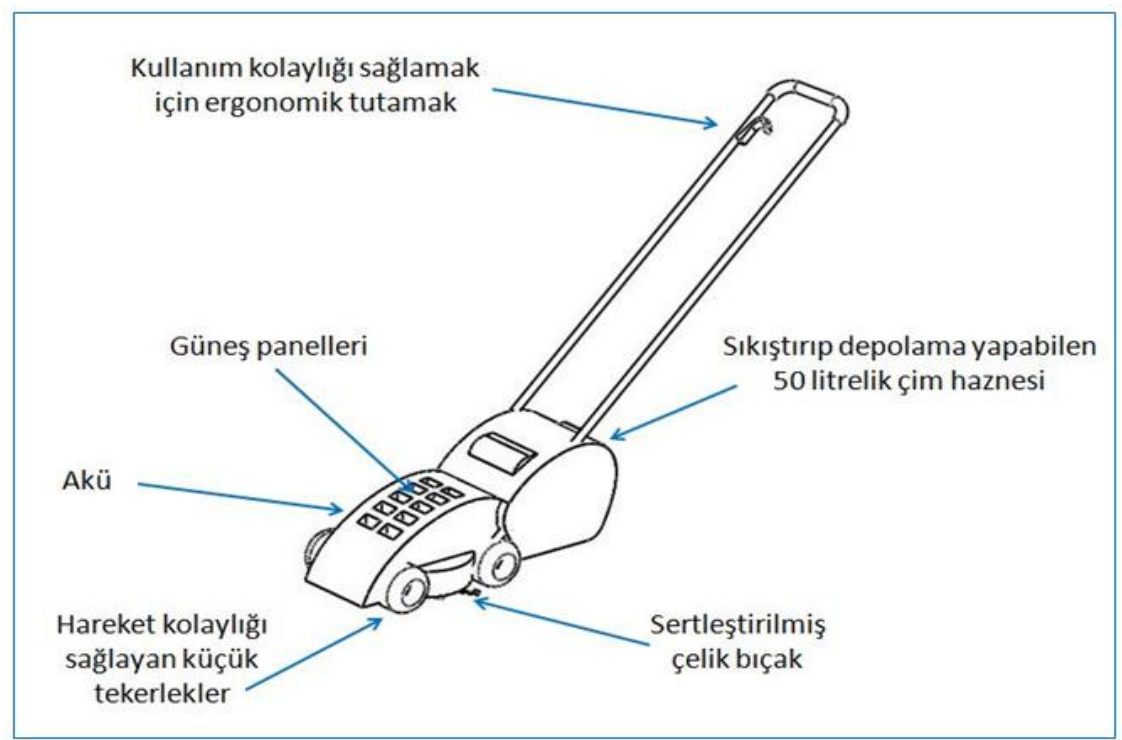

Şekil 6. Çim biçme makinesi kavramsal tasarımlar (Seçim 3)

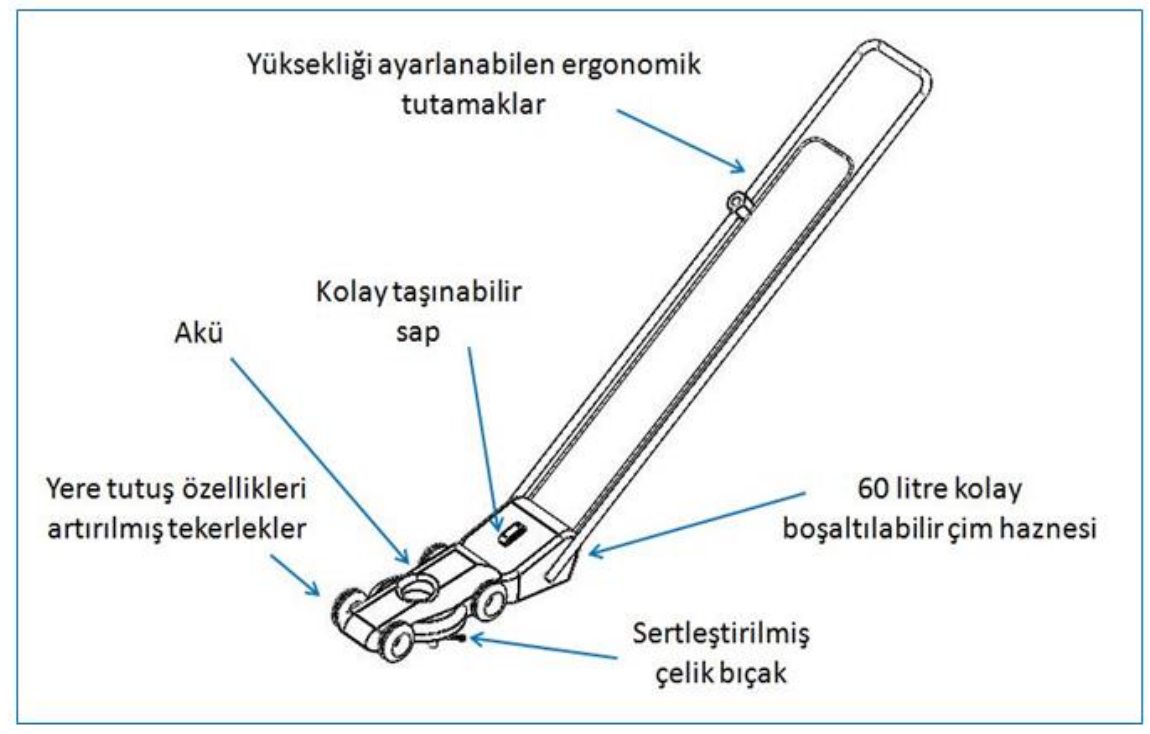

Şekil 7. Çim biçme makinesi kavramsal tasarımlar (Seçim 5)

\section{D.EK SEÇIM İŞLEMLERI}

Şekil 4'de bulunan seçim kartı kullanılarak kavramsal tasarım seçenekleri azaltılmakta ve altıdan üçe düşürülmektedir. $\mathrm{Bu}$ aşamada ön elemeyi geçen üç seçenek daha detaylı bir seçim işlemine tabi tutulmakta ve en ideal tasarım seçeneği kalacak şekilde işlem sürmektedir. Bu amaçla Şekil 8 de gösterilen bir amaçlar ağacı oluşturulmakta ve burada önem durumuna göre ölçütlere ağırlık (yüzde) 
değeri verilmektedir. Amaçlar ağacının en üst kutucuğunda bulunan $\left(\mathrm{W}_{\mathrm{t}}\right)$ değeri, amaçlar ağacının altında kalan değerlerin toplanması ile elde edilir.

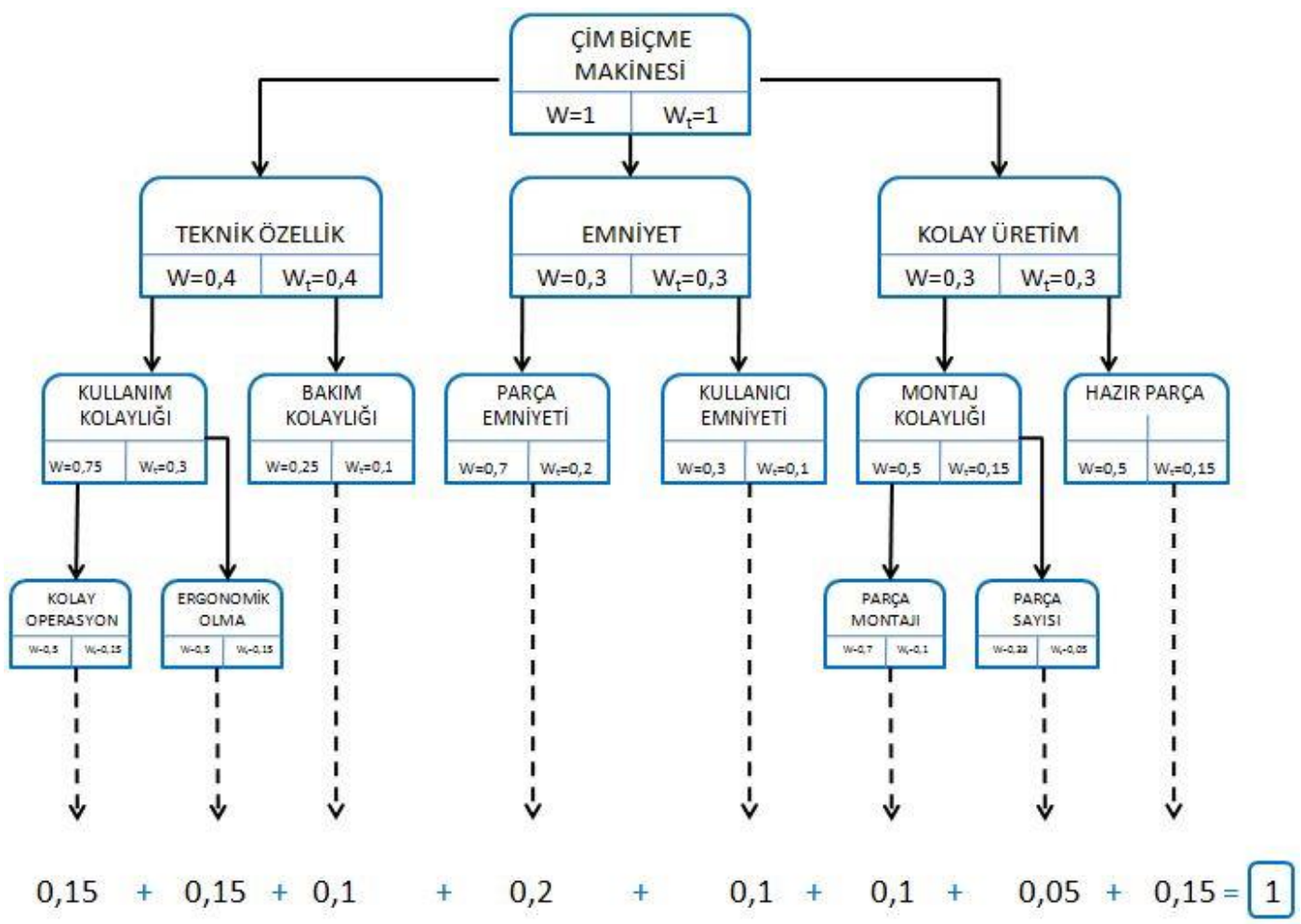

Şekil 8. Tasarıma ait oluşturulan amaçlar ağacı (kriter değer şeması)

\begin{tabular}{|c|c|c|c|c|c|c|c|c|c|c|c|c|}
\hline \multicolumn{4}{|c|}{ DEĞERLENDIRME ÇIZELGESİ } & \multicolumn{3}{|c|}{ SEÇENEK 2} & \multicolumn{3}{|c|}{ SEÇENEK 3} & \multicolumn{3}{|c|}{ SEÇENEK 5} \\
\hline & KRITER & w & PARAMETRELER & ORAN & DEĞER & 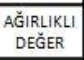 & ORAN & DEĞER & 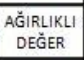 & ORAN & DEĞER & \begin{tabular}{|l}
$A G ̆ \mid R L I K L$ \\
DEĞER \\
\end{tabular} \\
\hline 1 & Kolay operasyon & 0,15 & Kolay kullanım & Fazla & 9 & 1,35 & Fazla & 9 & 1,35 & Fazla & 9 & 1,35 \\
\hline 2 & Ergonomik olma & 0,15 & Ergonomiklik & Fazla & 9 & 1,35 & Fazla & 9 & 1,35 & Fazla & 9 & 1,35 \\
\hline 3 & Bakım kolaylığı & 0,1 & Kolay bakım & Orta & 5 & 0,5 & Orta & 6 & 0,6 & Orta & 7 & 0,7 \\
\hline 4 & Parça emniyeti & 0,2 & Güvenirlik & Orta & 6 & 1,2 & Fazla & 8 & 1,6 & Orta & 6 & 1,2 \\
\hline 5 & Kullanıcı emniyeti & 0,1 & Emniyet & Orta & 7 & 0,7 & Fazla & 8 & 0,8 & Orta & 7 & 0,7 \\
\hline 6 & Parça montajı & 0,1 & Açık montaj işlemi & Orta & 6 & 0,6 & Fazla & 9 & 0,9 & Fazla & 9 & 0,9 \\
\hline 7 & Parça sayısı & 0,05 & Parça sayısı & Fazla & 8 & 0,4 & Orta & 7 & 0,35 & Fazla & 8 & 0,4 \\
\hline 8 & Hazır parça & 0,15 & Standart parça & Orta & 7 & 1,05 & Fazla & 9 & 1,35 & Fazla & 9 & 1,35 \\
\hline & & & & & & & & & & & $t_{5}$ & $7 c$ \\
\hline
\end{tabular}

Şekil 9. Tasarıma ait değerlendirme çizelgesi

Burada bulunan ölçütler ve değerler kullanılarak Şekil 9'da görülen bir değerlendirme çizelgesi oluşturulmaktadır. Değerlendirme çizelgesinde; önce ölçütler teknik parametrelere dönüştürülmekte ve bunlara (mümkünse) birimler atanmakta, son olarak da eldeki üç seçeneğe bu parametrelere göre 
puanlar verilmektedir. Seçenek puanları toplandığında 3 ve 5 nolu seçeneklerin 2 nolu seçenekten daha yüksek toplam puana sahip olduğu görülmektedir. Böylece tasarım seçenek sayısı 2'ye düşürülmektedir.

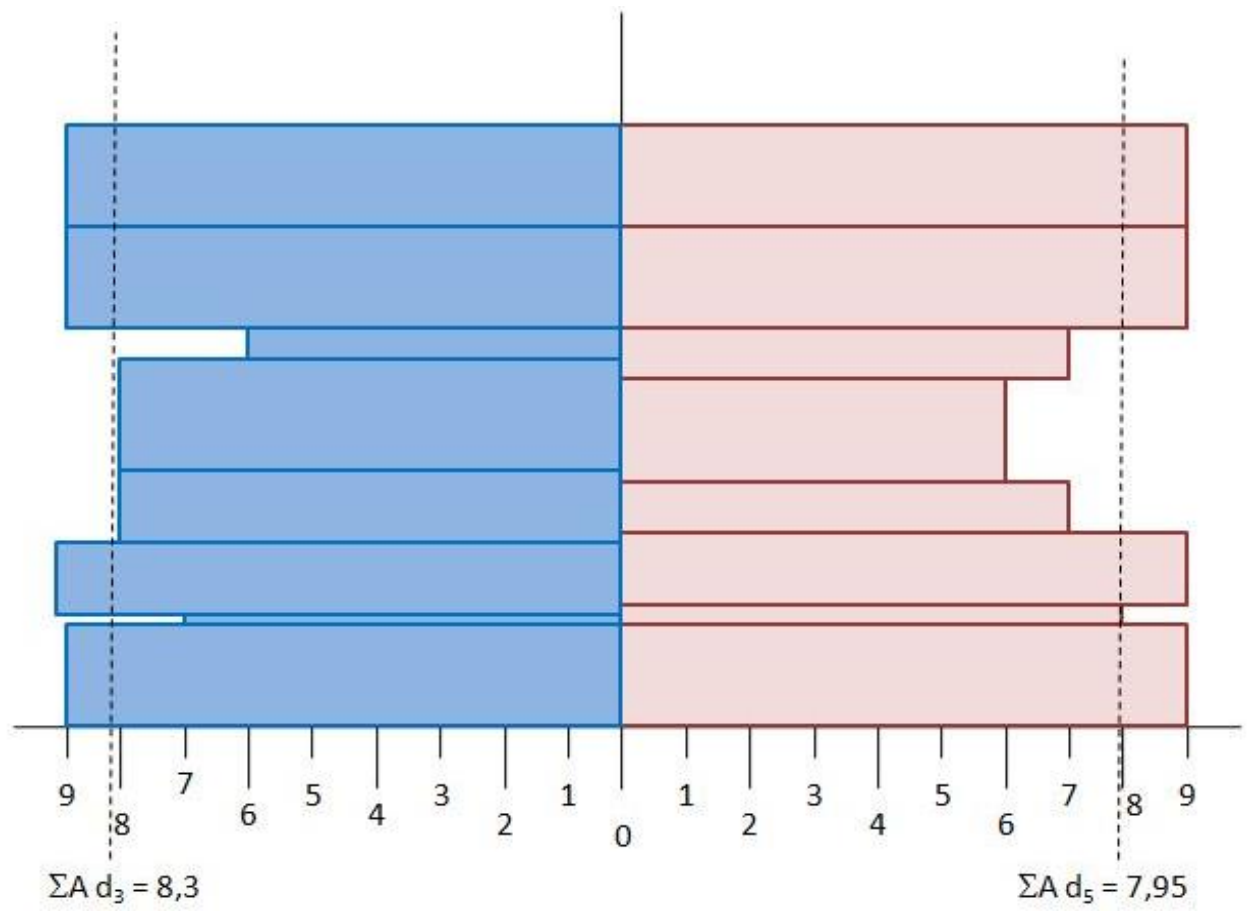

Şekil 10. Tasarıma ait değer profil diyagramı[9]

Bu aşamadaki son işlem, bu 2 seçeneğin bulunduğu şekil 10'da gösterilen değer profil diyagramını hazırlamayı içermektedir. Hazırlanan diyagramda Şekil 9 da gösterilen değer profil çizelgesinde elde edilen toplam ağırlık oranları sınır koşul kabul edilerek her bir parametrenin ağırlık değeri diyagramdaki kalınlıkları ve her bir değer genişlikleri gösterecek şekilde değer profil diyagramı çizilmiştir. Sınır koşulları Şekil 9 da hesaplanmıştır. Bu hesaplamaların muhakemesi neticesinde en iyi tasarım seçeneklerinden en yüksek değerli olanlar 3. tasarım seçeneği $\Sigma \mathrm{Ad}_{3}=8,3$ ve 5 . tasarım seçeneği $\Sigma \mathrm{Ad}_{5}=7,95$ ağırlıklı olanlar arasında bir tasarım seçilmesi gerekliliği ortaya çıkmıştır. Bu iki seçenek arasında da en yüksek ağıllık değerine sahip olan 3. tasarım seçeneği $\Sigma \mathrm{Ad}_{3}=8,3$ seçeneği muhtemel en iyi tasarım seçeneği olarak belirlenmiştir. Sınır koşul ile parametre sütunları arasındaki mesafe o seçenekte bulunan eksiklikleri göstermektedir. Hangi seçenekte eksikler (zayıf noktalar) daha az ise o seçenek en iyi/ideal veya optimum tasarımı oluşturmaktadır [15,17].

\section{F.DE $\breve{G E R L E N D I R M E ~ v e ~ S O N ~ K A R A R ~}$}

Ölçüm ve seçim işlemleri sonucu 3 nolu seçenek en iyi çim biçme makine tasarımı olarak belirlenmiştir. Böylece başta belirlenen özellikleri optimize ederek en optimum ve ihtiyaçlarımızı karşılayabilecek bir makine tasarımı gerçekleştirmiştir. Bu sistem; kolay kullanım için ergonomik tutamaklar, sıkıştırıp depolama yapabilen 50 litre çim haznesi, 5 kademe ayarlanabilir çelik bıçak, hareket kolaylığı sağlayan küçük tekerlek ve güneş panelleri ile akü şarjı sağlayan bir makinedir. Şekil 11 de tasarıma ait görünüm verilmiştir. 


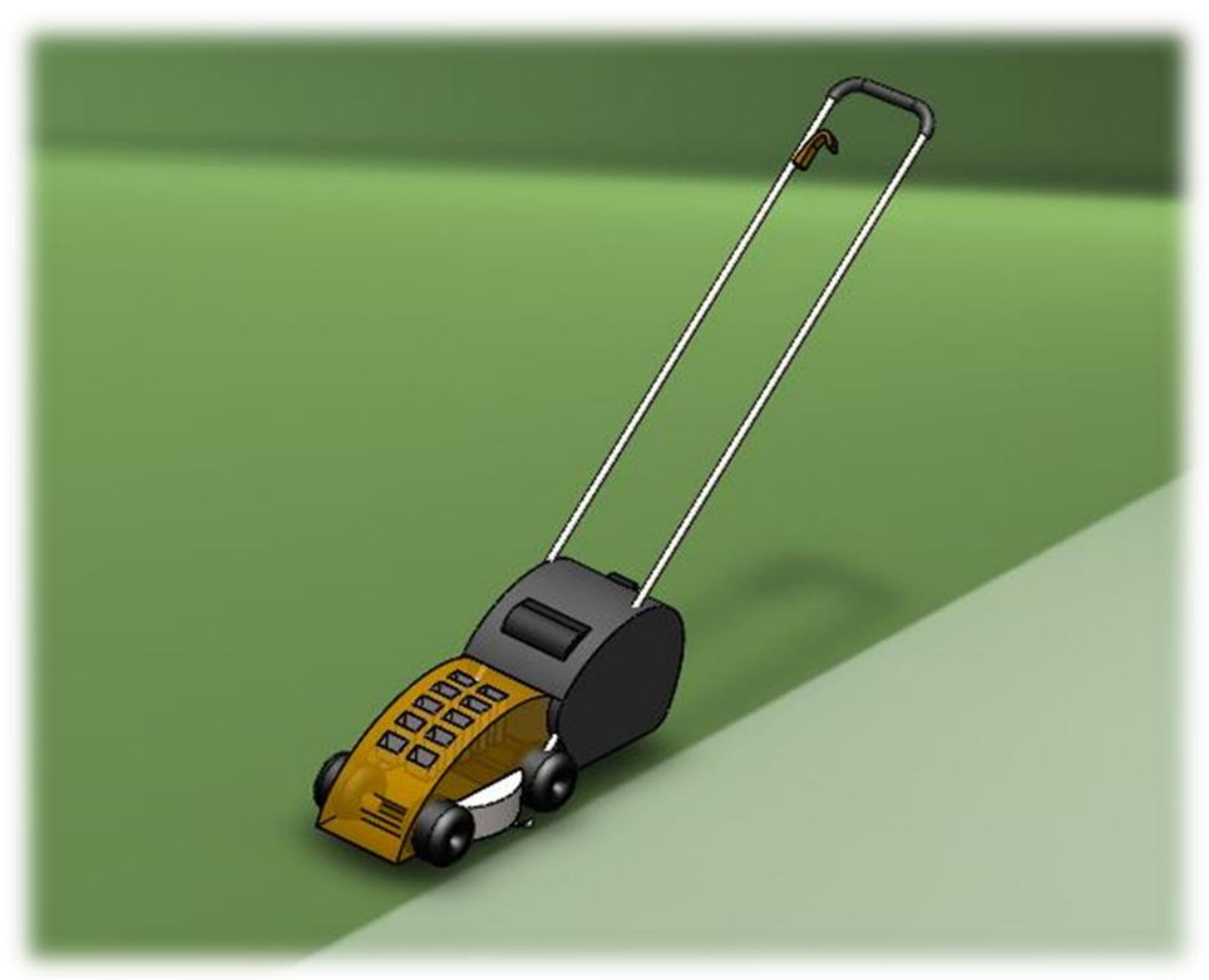

Şekil 11. En optimum olarak belirlenen kavramsal tasarım (Seçenek 3)

\section{SONUÇ}

$\mathrm{Bu}$ çalışma ile sistematik tasarım yaklaşım metodolojisi kullanılarak yeni bir çim biçme makinasının tasarımının geliştirilmesi için kavramsal bir tasarım yaklaşımıyla yeni bir tasarım süreci baştan sona irdelenmiştir. Kavramsal tasarımın esas amacı; temel ve detay mühendisliğe geçilmeden önce ortaya çıkartılması istenen ürünün ya da üründe bulunması istenen fonksiyonların gerekliliklerini tanımlamaktır. Bu amaçlar doğrultusunda (A) İhtiyaç listesi, (B) Fonksiyon şeması, (C) Alt ve genel tasarımlar, (D) Ön değerlendirme, (E) Önemli tasarımlar ve (F) Ek seçim işlemleri gibi genel bir çalışma metodolojisi izlenmiştir. $\mathrm{Bu}$ kriterlere göre incelenen tasarım için çeşitli seçenekler oluşturulmuştur. Çalışmada kavramsal tasarımı yapılan model için alt fonksiyonlara ait birçok alternatif olduğu görülmektedir. Bu alt tasarımlardan; elde edilen tasarım varyasyonlarından sistematik tasarım yaklaşımıyla performansı en yüksek değerde olan çözüm seçilerek tasarım işlemi tamamlanmıştır. Böylece önemli sistematik tasarım adımları ortaya inovatif (yenilikçi) değeri olan bir ürün tasarım ortaya çıkmıştır. Çalışma, bir ürün tasarlarken veya geliştirme süreci gerçekleştirilirken izlenecek ara tasarım yöntemlerinin gösterimi açısından örnek teşkil etmektedir. Kavramsal tasarım, bir ürünün ana özelliklerinin ve alt fonksiyonlarının belirlenmesini sağlamaktadır. Üretmenin mümkün olup olmadığını sorgulamak ayrıntılı yapılacak tasarım çalışmalarında ele alınmıştır. Yapılan çalışma bu alanda yapılacak çalışmalara kılavuz olabileceği gibi üzerinde yapılacak geliştirmelere de açıktır. 


\section{KAYNAKLAR}

[1] Y.YALÇIN MENDİ, (20 Şubat 2018$). \quad$ [Online]. Erişim:http://bahcebitkileri.cu.edu.tr/upload/ymendi/cimyetistiriciligi.pdf

[2] N. Uluocak 'Yer örtücü Bitkiler' İstanbul Üniversitesi Orman Fakültesi Havza Amenajmanı Anabilim Dalı Üniversite Yayın No:3874, Fakülte Yayın No:428, İstanbul 1994.

[3] ANONIM, (15 Mart 2018). [Online]. Erişim: http://www.ilkkimbuldu.com/cim-bicmemakinesini-kim-buldu/

[4] ANONIM, (15 Mart 2018). [Online]. Erişim:https://en.wikipedia.org/wiki/Lawn_mower

[5] G. L Rowe ve H. P Spindler, 'Lawn mower", United States Patent Office, US2926926A, 01 March 1960.

[6] R. D. Davis ve J. S. Schucker, "Self Propelled Lawn Mower", United States Patent Office, US4395865A, 28 January 1981.

[7] L. M. Medina, "Hybrıd Remote Control Lawn Mower", United States Patent Office, US10912324, 05 August 2004.

[8] J. Björn ve P. Jägenstedt, "Robotic Lawnmower", United States Patent Office, US20150045948A1, 12 February 2015.

[9] G. Pahl and W. Beitz,” Engineering Design, A systematic approach”, Third Edition, Springer, Verlag, 1984.

[10] M. Bozdemir ve İ.Toktaş," Mekanik Sistemlerin Kavramsal Tasarımına Sistematik Bir Yaklaşım”, Pamukkale Üniversitesi Mühendislik Bilimleri Dergisi, c. 7, s. 2, ss. 165-171, 2001.

[11] M. Mayda, ve H.R. Börklü, "Yeni Bir Kavramsal Tasarım İşlem Modeli”, TUBAV Bilim Dergisi, c. 1, s. 1, ss. 13-25, 2008.

[12] R. Ç. Orman ve Y. İçingür,” Yeşil Alan Makinesi Tasarımı ve İmalatı”, 27. Tarımsal Mekanizasyon Ulusal Kongresi, Samsun, Türkiye, 2012, ss. 441-452.

[13] J.A. Beno ," CWRU Cutter: Design and Control of An Autonomous Lawn Mowing Robot" PhD Thesis, Case Western Reserve University, USA, 2010.

[14] N. Nagarajan, N. S. Sivakumar ve R. Saravanan, "Design and Fabrication of Lawn Mower," Asian J. of Applied Sc.and Technology (AJAST), vol. 1, no. 4, pp. 50-54, 2017.

[15] H.R. Börklü, (Türkçeye Çeviren), Pahl, G.,Beitz, W., Feldhusen, G., Grote, K.H., Mühendislik Tasarımı: Sistematik Yaklaşım, 1. Baskı, Ankara ,Türkiye, Hatiboğlu Yayınları, 2010. 
[16] M. Mayda, ve H. R. Börklü, “ An integration of TRIZ and the systematic approach of Pahl and Beitz for innovative conceptual design process,” J. Braz. Soc. Mech. Sci. Eng., vol. 36, pp. 859-870, 2014.

[17] M. Mayda, ve H. R. Börklü, “ Development of an innovative conceptual design process by using Pahl and Beitz's systematic design, TRIZ and QFD, "Journal of Advanced Mechanical Design, Systems, and Manufacturing, vol. 8, no. 3, pp. 1-12, 2014. 